\title{
Connexin 32 regulates hepatoma cell metastasis and proliferation via the p53 and Akt pathways
}

\author{
Bixing Zhao ${ }^{1,2}$, Wenxiu Zhao ${ }^{1,2}$, Yu Wang ${ }^{1,2}$, Yaping $X \mathbf{u}^{1,2}$, Jianfeng $X u^{1,2}$, Kai Tang ${ }^{1,2}$, \\ Sheng Zhang ${ }^{1,2}$, Zhenyu Yin ${ }^{1,2}$, Qiao $\mathbf{W u}^{3}$, Xiaomin Wang ${ }^{1,2}$ \\ ${ }^{1}$ Department of Hepatobiliary Surgery, Zhongshan Hospital, Xiamen University. Fujian Provincial Key Laboratory of Chronic \\ Liver Disease and Hepatocellular Carcinoma, Xiamen University Affiliated Zhongshan Hospital \\ ${ }^{2}$ Research Institute of Digestive Disease, Xiamen University, Xiamen, Fujian, China \\ ${ }^{3}$ State Key Laboratory of Cellular Stress Biology, Innovation Center for Cell Biology, School of Life Sciences, Xiamen University, \\ Xiamen, Fujian Province, China
}

Correspondence to:

Xiaomin Wang, e-mail: wxm2203@xmu.edu.cn

Wenxiu Zhao, e-mail: wxzhao@xmu.edu.cn

Keywords: connexin32, p53, hepatocellular carcinoma, invasion, migration

Received: August 13, $2014 \quad$ Accepted: November 02, $2014 \quad$ Published: November 27, 2014

\section{ABSTRACT}

Hepatocellular carcinoma (HCC) progresses rapidly and is frequently associated with vascular invasion, metastasis, recurrence, and poor prognosis. The expression of connexin 32 (Cx32) is frequently downregulated in HCC tissues. In this study, the role of Cx32 in HCC metastasis and proliferation was investigated. The reduction of $\mathrm{C} \times 32$ in HCC tissues was significantly associated with increased vascular invasion, increased tumor size, and poor survival. In vitro assays revealed that Cx32 not only suppressed the invasion and migration of HCC cells, but also repressed HCC cell proliferation. Subsequent investigations revealed that $\mathrm{C} \times 32$ directly enhanced the acetylation and transcriptional activity of p53, thus upregulating the expression of the tumor metastasis suppressor protein KAI1/CD82, which is a p53 target gene. Additionally, Cx32 negatively regulated the phosphorylation of Akt and the expression of the cell cycle regulation protein cyclin D1, thereby inhibiting the proliferation of HCC cells. Our in vivo nude mice model further confirmed that Cx32 is able to suppress HCC tumor growth and metastasis in nude mice. Our results imply that Cx32 downregulation contributes to the proliferation and metastasis of HCC, and the restoration of $\mathrm{Cx} 32$ expression may be a promising strategy for HCC therapy.

\section{INTRODUCTION}

HCC is the fifth most common human cancer and the third leading cause of cancer death worldwide [1]. Frequent metastasis is responsible for the rapid recurrence of $\mathrm{HCC}$ and the poor survival in affected patients. However, the molecular mechanisms underlying HCC development and metastasis have not been elucidated.

Recently, molecularly targeted drugs for HCC treatment have been extensively studied. Multiple molecular pathways are implicated in HCC pathogenesis, including pathways involving vascular endothelial growth factor receptor (VEGFR), fibroblast growth factor receptor (FGFR), platelet-derived growth factor receptor (PDGFR), epidermal growth factor receptor (EGFR) [2], and hepatocyte growth factor (HGF)/c-MET [3] and the PI3K/ AKT/mTOR pathway [4]. An increasing number of HCCrelated signaling pathways may act as potential targets for therapeutic interventions. For example, Sorafenib, which is the only standard drug used for the treatment of patients with advanced HCC, is an oral multi-kinase inhibitor that blocks multiple growth factor pathways, including those involving VEGFR-1, -2, -3, PDGFR- $\beta$, Raf, RET, and FLT-3 [5].

Gap junction channels, which are located at cellcell contact sites, are composed of connexins (Cxs) and mediate the inter-cellular flux of metabolites, nutrients, and secondary messengers $[6,7]$. Gap junction 
intercellular communication and Cxs play important roles in organ/tissue homeostasis and cell differentiation $[6,8]$. Individual Cxs are defined and named based on their molecular weight and differ both in terms of function and expression patterns [9]. $\mathrm{Cx} 32$ and $\mathrm{Cx} 26$ are the main gap junction proteins in hepatocytes [6]. A previous study showed evidence that strongly supports the hypothesis that $\mathrm{Cx}$ genes act as tumor suppressor genes [10]. However, newer data now suggest that they may also play a role in tumor progression. Several reports suggest that Cxs might facilitate invasion, intravasation, extravasation, and metastasis [11-13]. Thus, studies examining the relationship between $\mathrm{Cxs}$ and tumor cell invasion have been controversial, and the findings should be clarified further.

Abnormal cell proliferation, which results from the deregulation of the cell cycle, forms the crux of the cancer phenotype. Accumulating evidence has clearly demonstrated a role for Cxs in cell proliferation. A decrease in cell proliferation was commonly observed in earlier studies that focused on the phenotypic changes in cancer cells following enhanced Cx expression [14]. One recent study verified that $\mathrm{Cxs}$ play an anti-proliferative role in various cancers, including HCC [15], gastric cancer [16], insulinomas [17], canine bone tumors [18], and non-small cell lung cancer [19]. Therefore, Cxs provide a unique perspective when studying specific aspects of cell cycle regulation, and these insights may help develop more focused therapies that target this process.

In this study, we demonstrate the significance of Cx32 in tumor cell proliferation and metastasis. First, we found that the downregulation of $\mathrm{Cx} 32$ in human HCC tissues was associated with increased tumor sizes, metastasis, and poor survival. In vitro and in vivo assays showed that Cx32 significantly suppressed HCC proliferation and metastasis. Additionally, we provided further evidence to support the notion that $\mathrm{Cx} 32$ exerts its anti-proliferative and anti-metastatic effects via the PI3K/ Akt and p53 pathways, respectively.

\section{RESULTS}

\section{Downregulation of $\mathrm{Cx} 32$ is associated with a poor prognosis}

Western blotting was first performed to examine the expression of $\mathrm{Cx} 32$ in 24 pairs of HCC specimens and adjacent non-tumorous liver samples (Fig. 1A). Quantitative analyses of Cx32 protein expression showed that compared to paired non-tumor tissues, $62.5 \%$ of HCC samples showed downregulated levels of $\mathrm{Cx} 32$ expression (Fig. 1C); there was a significant difference in relative $\mathrm{Cx} 32$ protein levels between paired tumor and non-tumor tissues ( $p=0.034$, Paired $t$-test; Fig. 1B). The Cx32 mRNA expression levels were further examined by quantitative real-time PCR in another set of 49 human HCC specimens. Similarly, Cx32 mRNA levels were also downregulated in HCC specimens ( $p=0.0373$, Paired $t$-test; Fig. 1B, 1C). The results of the immunohistochemical analysis of $\mathrm{Cx} 32$ expression in sections from paraffin-embedded HCC samples were consistent with those derived from the realtime PCR and western blot analyses (Fig. 1D). Therefore, the downregulation of $\mathrm{Cx} 32$ observed in HCC specimens suggests that $\mathrm{Cx} 32$ may be involved in $\mathrm{HCC}$ progression.

To understand the significance of $\mathrm{Cx} 32$ in $\mathrm{HCC}$ better, we analyzed the correlation between Cx32 mRNA levels and the clinical features of the HCC patients evaluated in this study (Table 1); the total number of cases used in the statistical analyses was 40 , owing to incomplete information on some patients. The median expression value of all 40 cases was chosen as the cutoff value for separating the dataset into a Cx32-low expression group and a Cx32-high expression group [20]. Kaplan-Meier analysis revealed an association between lower $\mathrm{Cx} 32$ expression levels and a shorter overall survival time (Fig. 1G). Importantly, lower Cx32 expression levels were significantly associated with large tumor size and vascular invasion (Table $1 \&$ Fig. 1E, 1F). Together, our findings suggest that $\mathrm{Cx} 32$ downregulation may contribute to $\mathrm{HCC}$ progression by promoting tumor growth and metastasis.

\section{Cx32 suppresses $\mathrm{HCC}$ cell migration and invasion}

To examine the expression of $\mathrm{Cx} 32$ in HCC cells further, a western blot analysis was performed in several HCC cell lines (HepG2, QGY-7701, SMMC-7721, and $\mathrm{MHCC} 97-\mathrm{H})$ (Fig. 2A). Cx32 protein levels were significantly higher in the HepG2 and QGY-7701 cells than in the MHCC97-H and SMMC-7721 cells, and the metastatic potential of the MHCC97H and SMMC-7721 cells was remarkably greater than that of the HepG2 and QGY-7701 cells (Fig. 2B). Therefore, we hypothesized that $\mathrm{Cx} 32$ may negatively regulate the migratory and invasive abilities of HCC cells.

To establish stable Cx32 knockdown cells, HepG2 cells were stably transfected with the pU6 (shCtrl) control vector or the pU6-Cx32-shRNA (shCx32) plasmid. Simultaneously, SMMC-7721 cells were transiently transfected with Cx32/pIRES2-EGFP to increase Cx32 expression. Cx32 expression in each cell line was demonstrated by a western blot analysis (Fig. 2C). shCx32-2, which was shown to result in a significant Cx32 knockdown, was used in subsequent experiments. To elucidate the role of $\mathrm{Cx} 32$ in HCC metastasis, the effects of Cx32 on the migration and invasiveness of HCC cells were analyzed. Transwell assays showed that both the migratory and invasive activities of HCC cells were suppressed by Cx32 overexpression, but were promoted 
A

\section{$\begin{array}{llllllll}\mathbf{T} & \mathbf{N} & \mathbf{T} & \mathbf{N} & \mathbf{T} & \mathbf{N} & \mathbf{T} & \mathbf{N}\end{array}$}

Cx32

Actin

Cx32

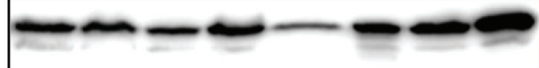

Actin

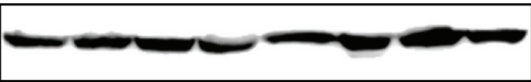

Cx32

Actin
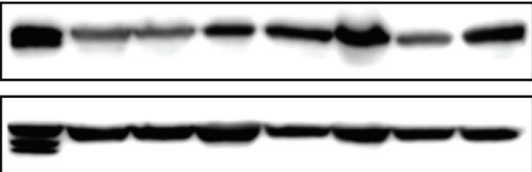

B

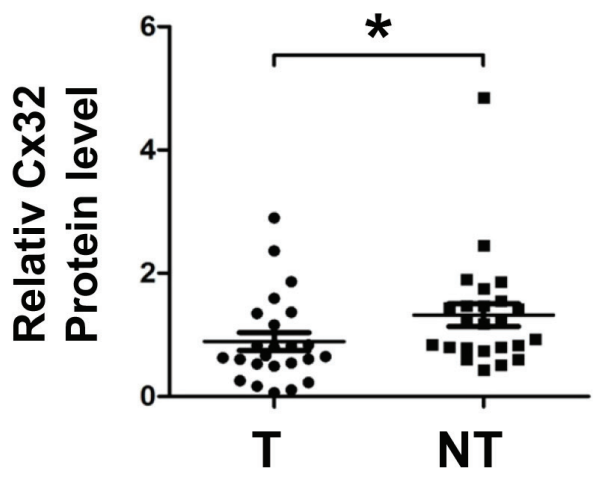

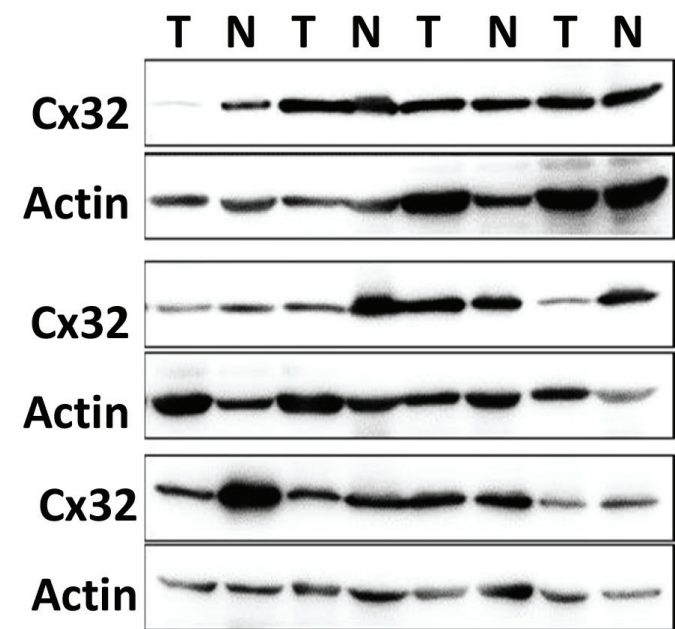

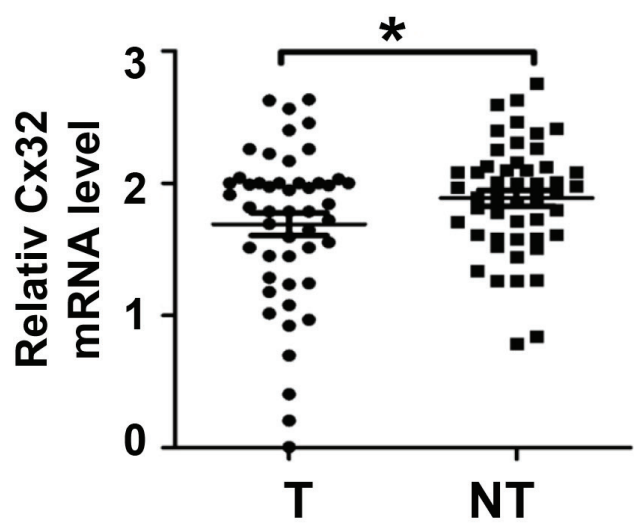

C

$$
\begin{array}{cc}
\text { With } & \text { Without } \\
\text { underexpression } & \text { underexpression }
\end{array}
$$

\section{Cx32 protein}

$62.5 \%(15 / 24)$

$37.5 \%(9 / 24)$

Cx32 mRNA

$59.2 \%(29 / 49)$

$40.8 \%(20 / 49)$

D
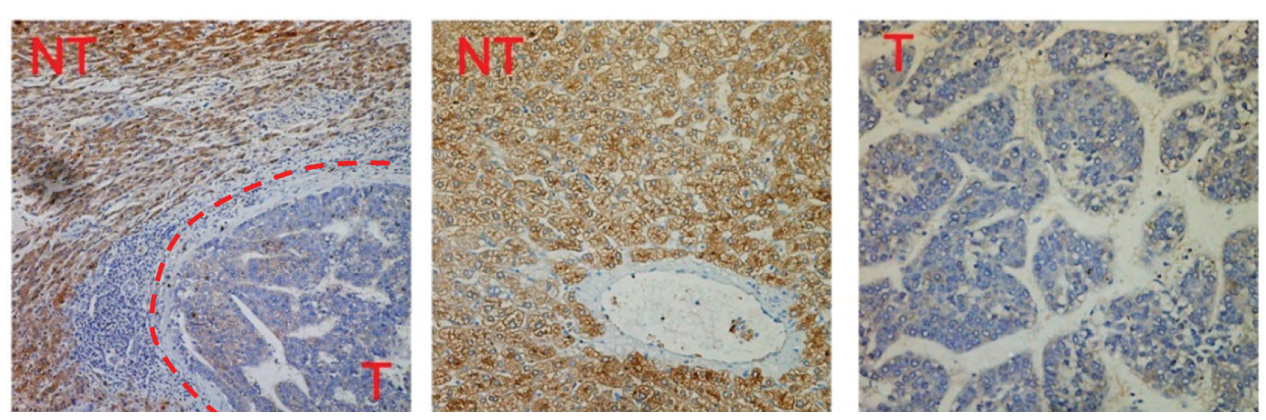

Figure 1: Downregulation of $\mathrm{Cx32}$ in $\mathrm{HCC}$ tissues is associated with a poor prognosis for HCC patients. (A) Western blot analysis of $\mathrm{Cx} 32$ protein expression in 24 human $\mathrm{HCC}$ samples and their adjacent non-tumorous liver tissue samples. N: non-tumorous liver tissue, T: tumor tissue. (B) Quantitative analysis of Cx32 protein expression in 24 human HCC samples and mRNA level analysis of Cx32 in another set of 49 HCC tumor samples (T) vs. non-tumor samples $(\mathrm{NT}) ;{ }^{*} p<0.05$.

(C) Summary of the differences in the expression of $\mathrm{Cx} 32$ protein and mRNA between paired tumor and non-tumor liver tissues.

(D) Immunohistochemical staining for Cx32 in HCC tumor tissue (T) and non-tumorous liver tissue (NT).

(Continued) 

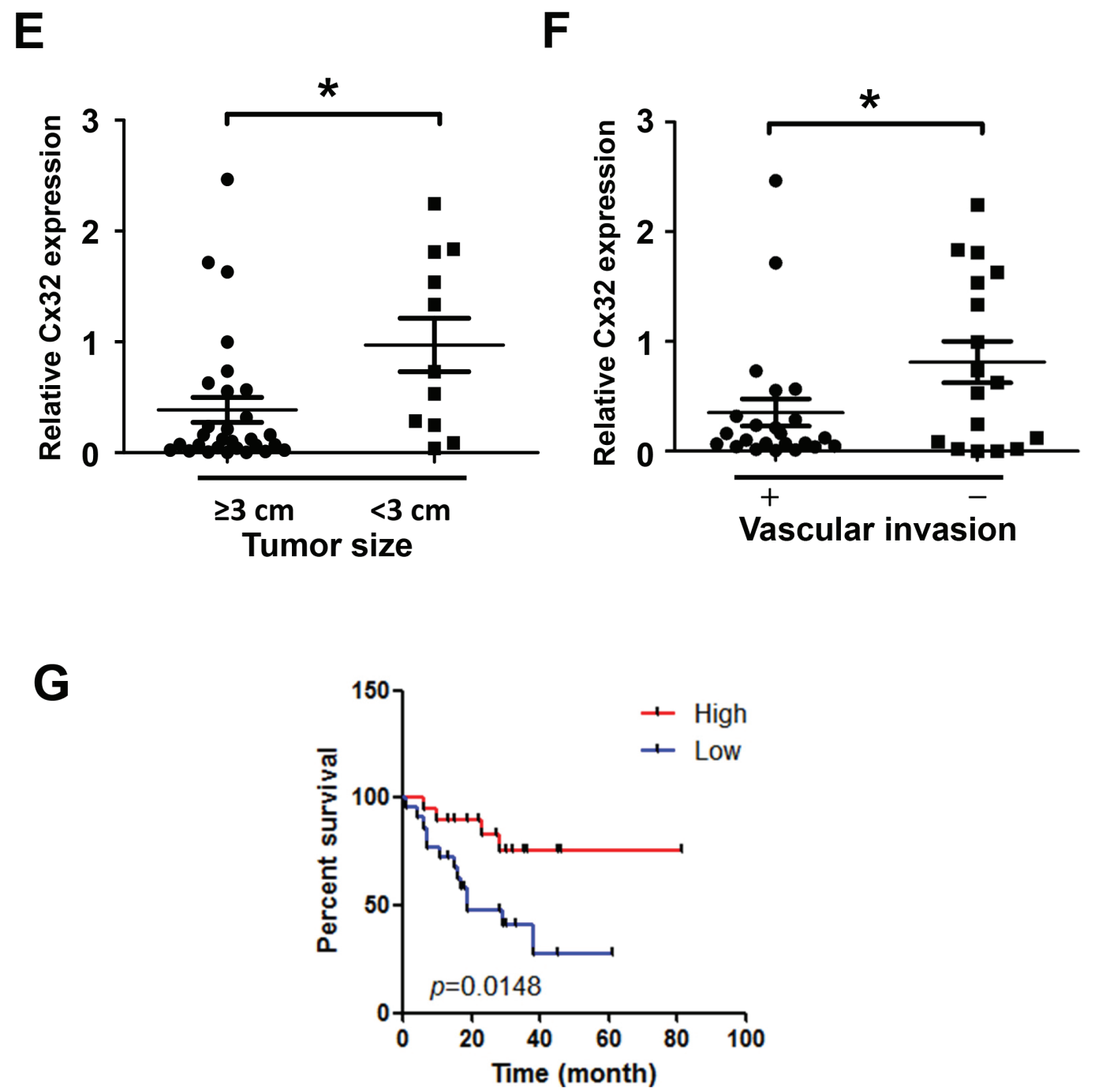

Figure 1 (Continued): (E) Tumor size was inversely correlated with Cx32 mRNA expression in HCC tissues. The median expression value of all 40 cases was chosen as the cutoff value for separating the dataset into a Cx32-low expression group and a Cx32-high expression group. (F) Metastatic HCC displayed lower Cx32 expression levels. The absence $(n=17)$ and presence $(n=23)$ of vascular invasion (tumor thrombus in the veins of adjacent non-tumor tissues or in the portal vein) is indicated with a minus sign $(-)$ and plus sign (+), respectively; $* p<0.05$. (G) Kaplan-Meier curves revealed an association of lower Cx32 levels with a shorter overall postoperative survival.

by cellular Cx32 depletion (Fig. 2D). The migration rate was also measured using a wound healing assay, and the results confirmed that $\mathrm{Cx} 32$ negatively regulates the migration rate of HCC cells (Fig. 2E).

Together, these results indicate the suppressive effects of $\mathrm{C} \times 32$ on $\mathrm{HCC}$ migration and invasiveness.

\section{$\mathrm{Cx} 32$ represses $\mathrm{HCC}$ metastasis via the $\mathbf{p 3}$ pathway}

To understand the mechanisms underlying the changes in the invasive and migratory abilities of HCC cells, the levels of several invasion-related proteins were compared between the control HepG2 cells and the Cx32-depleted HepG2 cells, using western blot analysis.
Downregulation of $\mathrm{Cx} 32$ did not cause a significant change in the expression of matrix metallopeptidase 2 (MMP2) or in that of VEGF, but did result in a significant decrease in the expression of KAI1/CD82, a tumor metastasis suppressor protein (Fig. 3A). The expression of CD82 in SMMC-7721 cells was increased following $\mathrm{Cx} 32$ overexpression (Fig. 3B). However, in the p53-null Hep3B cells, overexpression of $\mathrm{Cx} 32$ failed to alter the expression of CD82 (Fig. 3B). Therefore, we believe that the upregulation of CD82 expression by $\mathrm{Cx} 32$ is p53-dependent because KAI1/CD82 transcription is also upregulated by p53 [21]. To confirm this notion, p53 was co-expressed in Hep3B cells; under these conditions, $\mathrm{Cx} 32$ was able to upregulate CD82 expression (Fig. 3B). 
Table 1: Correlation of Cx32 mRNA expression with clinicopathological features in hepatocellular carcinoma

\begin{tabular}{|c|c|c|c|}
\hline Variables & Category & Number of Case & $P$ Vlaue \\
\hline \multirow{2}{*}{ Age } & $<59$ & 28 & \multirow{2}{*}{0.3759} \\
\hline & $\geq 59$ & 12 & \\
\hline \multirow{2}{*}{ Gender } & Male & 34 & \multirow{2}{*}{0.7956} \\
\hline & Female & 6 & \\
\hline \multirow{2}{*}{ Tumor size } & $\geq 3 \mathrm{~cm}$ & 29 & \multirow{2}{*}{$0.0169 *$} \\
\hline & $<3 \mathrm{~cm}$ & 11 & \\
\hline \multirow{2}{*}{ Vascular invasion } & Yes & 23 & \multirow{2}{*}{$0.0395 *$} \\
\hline & No & 17 & \\
\hline \multirow{2}{*}{$\operatorname{AFP}(n g / m l)$} & $>200$ & 16 & \multirow{2}{*}{0.3667} \\
\hline & $\leq 200$ & 24 & \\
\hline \multirow{2}{*}{ HBsAg } & Negative & 6 & \multirow{2}{*}{0.4716} \\
\hline & Positive & 34 & \\
\hline \multirow{2}{*}{ Cirrhosis } & Absent & 11 & \multirow{2}{*}{0.3595} \\
\hline & Present & 29 & \\
\hline \multirow{2}{*}{ TNM stage } & I-II & 5 & \multirow{2}{*}{0.2056} \\
\hline & III-IV & 35 & \\
\hline
\end{tabular}

Abbreviation: AFP, alpha-fetoprotein.

$* P<0.05$.

A

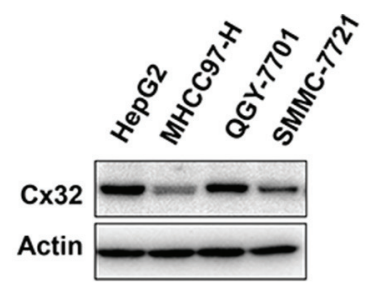

B

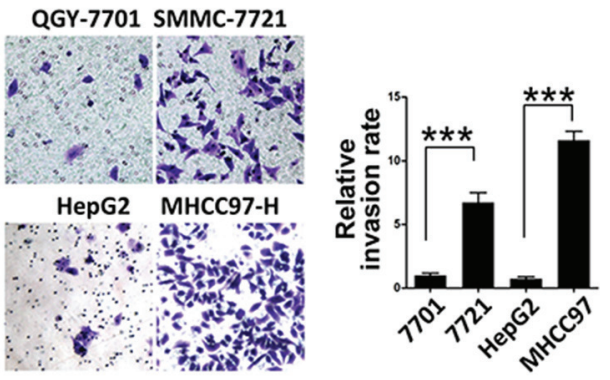

Figure 2: Cx32 represses HCC cell invasion and migration. (A) Western blot analysis of Cx32 protein expression in one hepatocyte cell line (L-O2) and four human HCC cell lines (HepG2, MHCC97-H, QGY-7701, and SMMC-7721). (B) Matrigel invasion assays of HepG2, MHCC97-H, QGY-7701, and SMMC-7721 cells.

(Continued) 


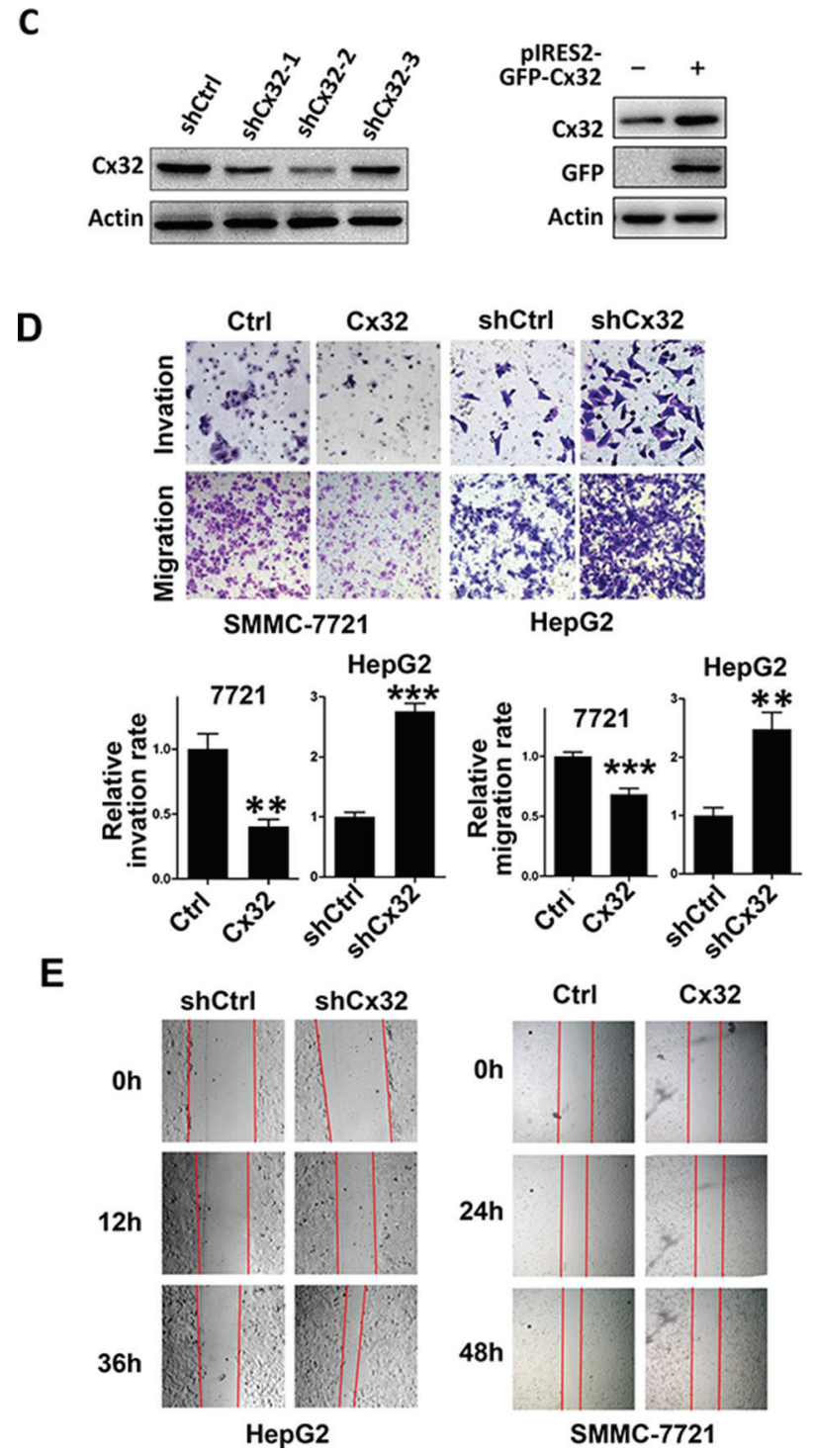

Figure 2 (Continued): (C) Western blot showing a marked reduction of Cx32 expression in knockdown HepG2 cells, and upregulation of Cx32 in SMMC-7721 cells transfected with the pIRES2-GFP-Cx32 expression vector. (D) Overexpression of Cx32 reduces SMMC7721 cell invasion and migration; downregulation of $\mathrm{Cx} 32$ promotes HepG2 cell invasion and migration. (E) Wound-healing assay showing that Cx32 inhibited the migration of SMMC-7721 cells and that downregulation of Cx32 promoted the migration of HepG2 cells.

Because p53 is the transcription activator of KAI1/CD82, Cx32 may lead to CD82 upregulation by merely increasing the transcriptional activity of $\mathrm{p} 53$. We investigated this possibility by using a p53-luciferase reporter system. As shown in Fig. 3C, Cx32 significantly induced the activity of the 53 reporter gene, and the addition of Cx32 siRNA significantly reduced p53 transcriptional activity.

It has been reported that acetylation of p53 by p300/ $\mathrm{CBP}$ on multiple lysine residues leads to the activation of p53 transcriptional activity [22]. Thus, it is possible that Cx32 affects p53 acetylation, leading to the induction of p53 transcriptional activity. To test this possibility, the acetylation level of p53 was tested using an antibody specific for p53 acetylation at K373/K382. As expected, $\mathrm{Cx} 32$ knockdown greatly decreased the acetylation level of $\mathrm{p} 53$, while $\mathrm{Cx} 32$ overexpression significantly induced p53 acetylation (Fig. 3D). We concluded that $\mathrm{Cx} 32$ could enhance p53 acetylation, which might contribute to the upregulation of p53 transcriptional activity, resulting in the upregulation of the downstream protein CD82.

Next, we confirmed our hypothesis by using a unique $\mathrm{p} 53$ point mutant, $\mathrm{p} 53 \mathrm{~K} 373 / \mathrm{K} 382 \mathrm{R}$. When this point mutant was transiently transfected into Hep3B cells, the introduction of $\mathrm{Cx} 32$ could not alter the expression level of CD82 in relation to the wild-type p53 group 
(Fig. 3B). Thus, this result showed that the Cx32-mediated induction of the CD82 protein is dependent on p53 acetylation.

One consequence of p53 acetylation is a decrease in p53 degradation [23]. To evaluate the effect of Cx32 on p53 protein stability, SMMC-7721 cells were treated with cycloheximide $(\mathrm{CHX})$, an inhibitor of protein synthesis. Western blot analysis (Fig. 3E) indicated that $\mathrm{Cx} 32$ significantly prolongs the half-life of $\mathrm{p} 53$.

To understand the mechanism by which $\mathrm{Cx} 32$ affects p53 acetylation, we examined histone deacetylase 1 (HDAC1), which directly regulates the deacetylation of p53. Previous studies have shown that restoration of $\mathrm{Cx} 32$ expression in Cx32-deficient hepatocytes results in a 2.5fold decrease in the expression of HDAC1 [24]. We also
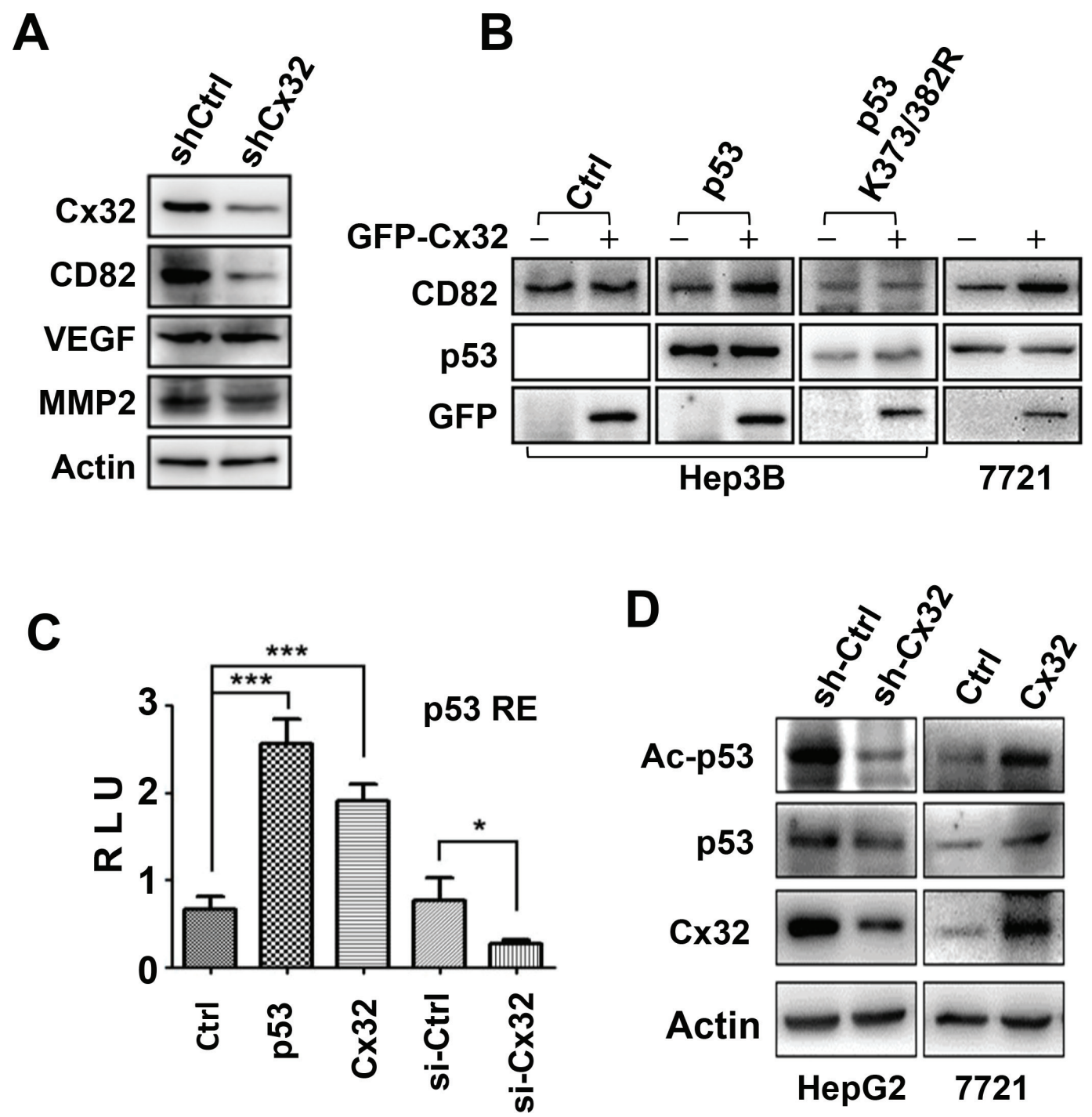

Figure 3: Cx32 exerts its anti-metastatic function via the p53-CD82 pathway. (A) The protein level of CD82 was downregulated in shCx32 HepG2 cells. (B) Cx32 upregulated the expression of CD82 in a p53-dependent manner. Cx32, p53, or p53 mutant (K373/382R) expression vectors were transfected into Hep3B or SMMC-7721 cells, as indicated, and the cells were monitored for the expression of CD82 by western blot. (C) Cx32 induced p53 transcriptional activity. The p53-Luciferase reporter and $\beta$-galactosidase ( $\beta$-gal) gene expression vectors, together with p53, Cx32 expression vectors, Cx32 siRNA, or siCtrl, as indicated, were transfected into $293 \mathrm{~T}$ cells. Reporter gene activity was determined and normalized in relation to the co-transfected $\beta$-gal activity. The bars represent the mean \pm SEM from three independent experiments. (D) Cx32 positively regulated p53 acetylation. Cx32 knockdown HepG2 cells and control cells were collected, and SMMC-7721 cells were non-transfected or transfected with the Cx32 expression vector for 48 h. Each cell lysate was then subjected to western blot analysis using an anti-Acetylated-p53 (K373/382), -Cx32, or -p53 antibody.

(Continued) 

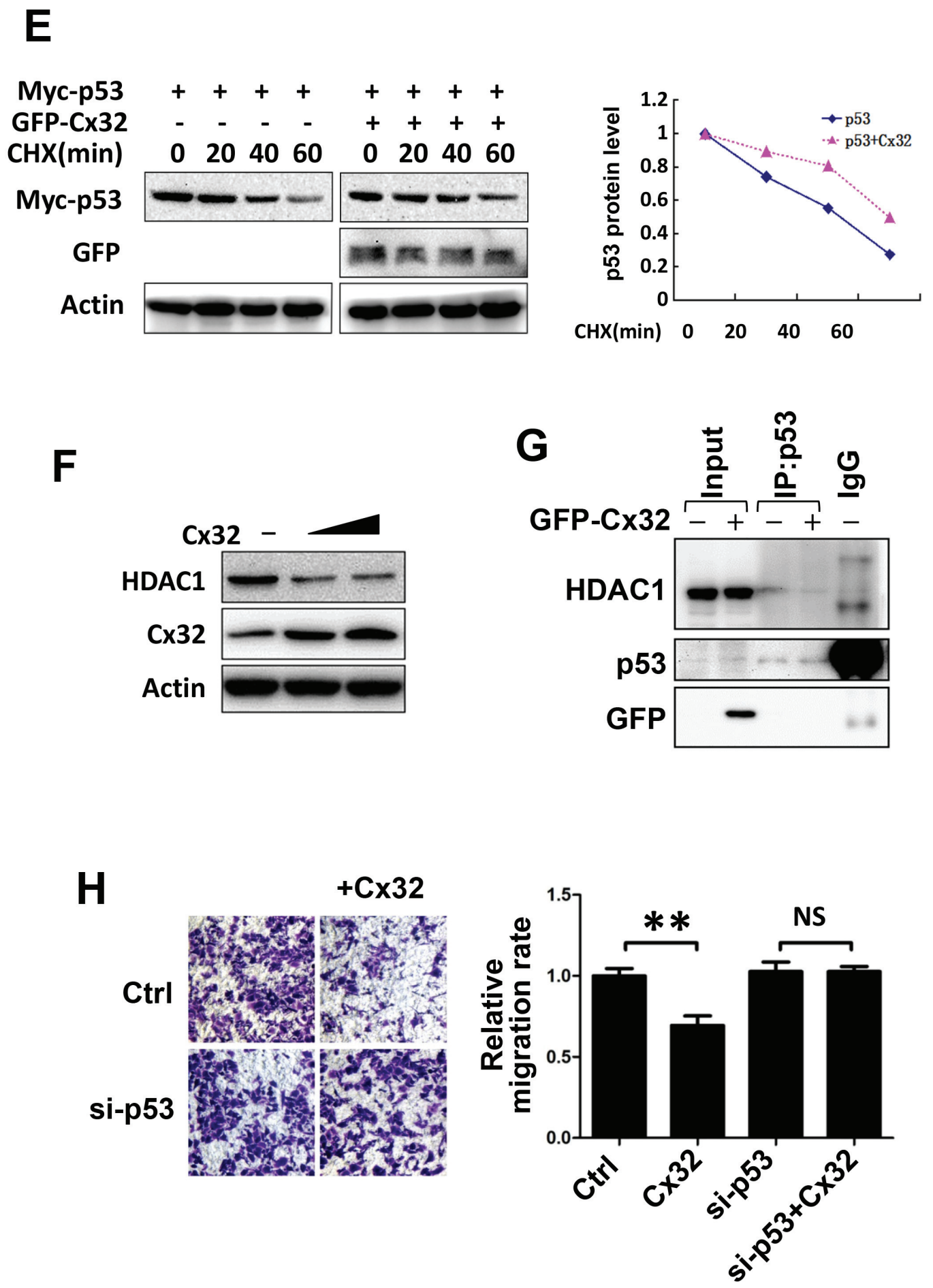

Figure 3 (Continued): (E) Cx32 prolongs the half-life of p53. Cx32 and Myc-p53 were transfected into 293T cells and then treated with CHX $(100 \mu \mathrm{g} / \mathrm{ml})$ for the indicated times. p53 expression level was determined by western blotting using an anti-Myc antibody. The levels of p53 protein were quantified by densitometry. (F) Cx32 inhibited HDAC1 expression in a dose-dependent manner. (G) $\mathrm{Cx} 32$ inhibited the interaction of p53 and HDAC1. GFP-Cx32 was transfected into SMMC-7721 cells, as indicated. The loading of HDAC1 was normalized before immunoprecipitation, and the cell lysate was then immunoprecipitated using an anti-p53 antibody. The immunoprecipitates were examined by western blotting using an anti-HDAC1 antibody. The input represented $10 \%$ of the cell lysates used in the co-IP experiment. (H) p53 siRNA attenuated the anti-migratory function of Cx32. SMMC-7721 cells were transfected with Cx32, siCtrl, or si-p53, as indicated. Twenty-four hours later, cells were added to transwell chambers and incubated for $20 \mathrm{~h}$, followed by staining with crystal violet; $* p<0.05 ; * * p<0.01 ; * * * p<0.001$. 
observed that $\mathrm{Cx} 32$ downregulated the level of HDAC1 protein in a dose-dependent manner in SMMC-7721 cells (Fig. 3F).

It has been reported that interactions between p53 and HDACs result in p53 deacetylation, thereby reducing p53 transcriptional activity [25]. We wondered whether Cx32 induces p53 acetylation and transcriptional activity by affecting the p53-HDAC1 interaction. To confirm this hypothesis, SMMC-7721 cells were transiently transfected with GFP-Cx32, and co-immunoprecipitation (co-IP) assays were performed. Because the introduction of $\mathrm{Cx} 32$ results in a decrease in HDAC1 protein levels, HDAC1 protein levels were normalized before the co-IP assay was performed. As expected, HDAC1 was detected in the p53 immunoprecipitate but not in the $\mathrm{IgG}$ immunoprecipitate, and transfection of $\mathrm{Cx} 32$ significantly suppressed the interaction between p53 and HDAC1 (Fig. 3G).

We next examined whether the negative regulatory effect of $\mathrm{Cx} 32$ on HCC cell metastasis was also dependent on p53. SMMC-7721 cells, which harbor wild-type p53 [26], were transiently transfected with p53 siRNA. As shown in Fig. 3H, Cx32 alone was able to inhibit cell migration. However, the addition of p53 siRNA drastically attenuated the inhibition of cell migration caused by $\mathrm{Cx} 32$.

These results confirmed the role of Cx32-p53-CD82 cross talk in the regulation of HCC cell migration and invasiveness.

\section{Cx32 suppresses HCC cell proliferation}

To investigate the role of $\mathrm{Cx} 32$ in $\mathrm{HCC}$ cell proliferation, an EdU assay was performed in stable Cx32-knockdown HepG2 cells and control HepG2 cells. As shown in Fig. 4A, Cx32-knockdown HepG2 cells (sh-Cx32) had a significantly higher positive rate for EdU incorporation than shCtrl HepG2 cells did (39.6\% vs. $24.5 \%$, respectively, $p=0.0025)$. Similarly, Cx32 overexpression in SMMC-7721 cells significantly

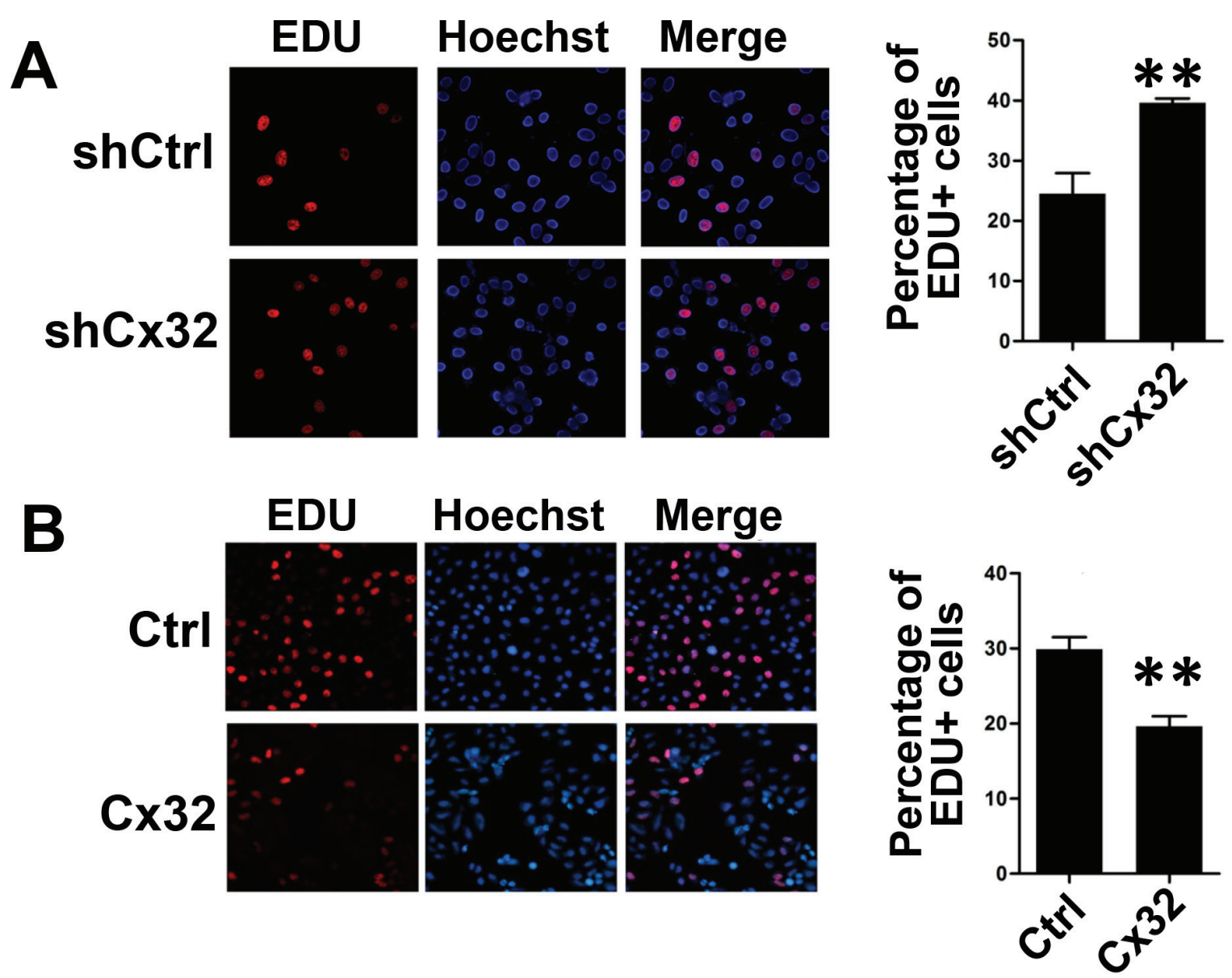

Figure 4: Cx32 suppresses HCC cell proliferation through inhibition of the Akt signaling pathway. (A, B) EdU assay analysis of the Cx32 knockdown (A) and overexpression (B) effect on the proliferation of HepG2 and SMMC-7721 cells. Cells were cultured in 24-well microtiter plates after transfection or non-transfection. EdU $(100 \mu \mathrm{M})$ was added, and the cells were cultured for another $2 \mathrm{~h}$ before EdU and Hoechst staining. The total cell number and EdU-positive cell number were counted in five random fields; $* * p<0.01$.

(Continued) 


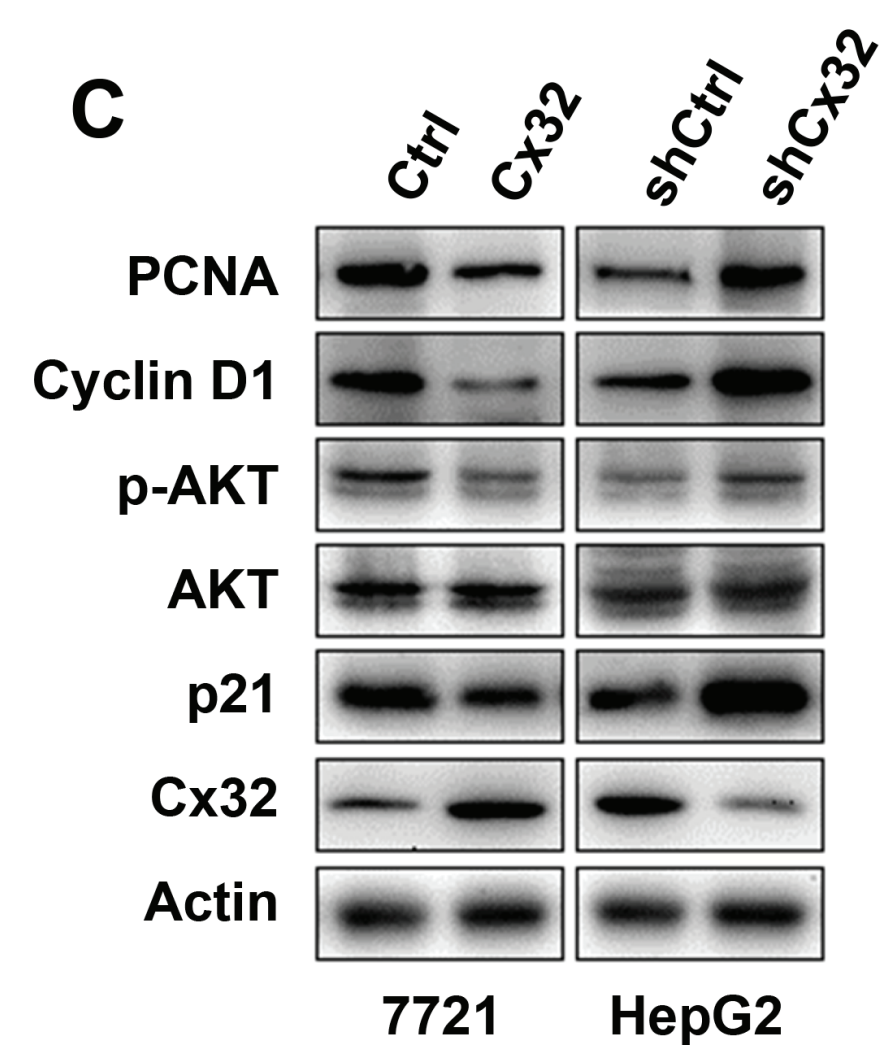

D
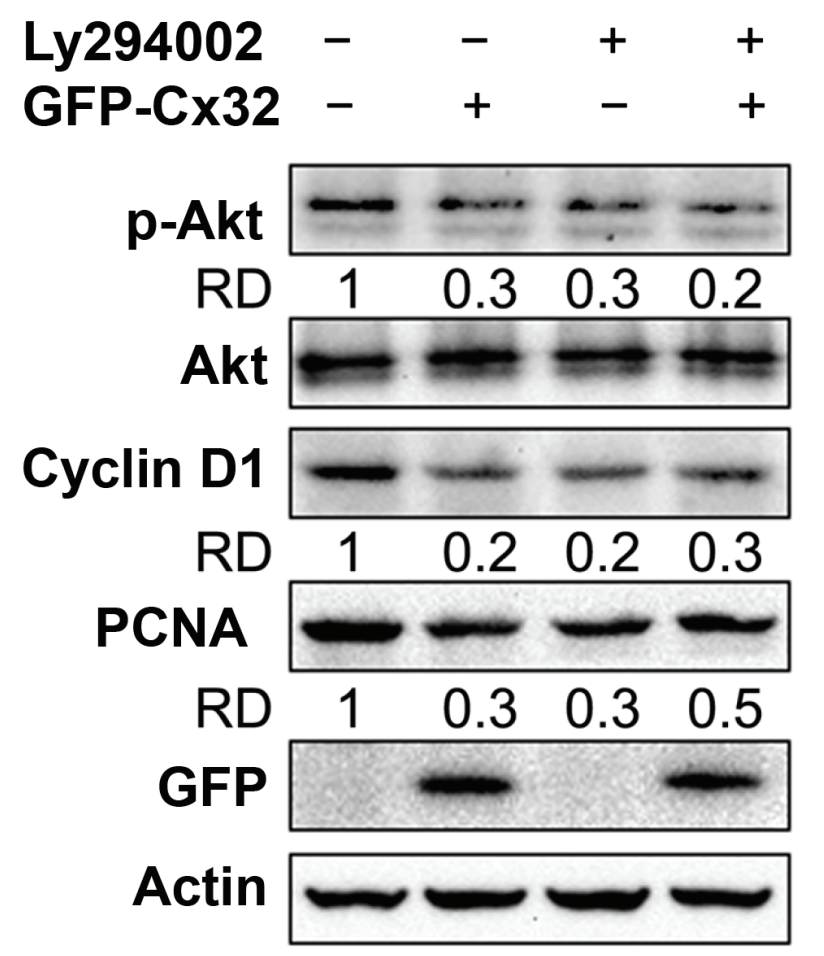

Figure 4 (Continued): (C) The expression of PCNA, Akt, and cell cycle regulatory proteins in Cx32-overexpression or knockdown HCC cells and control cells. (D) The PI3K inhibitor attenuated the inhibitory function of Cx32 on PCNA and cyclin D1 protein levels, as examined by western blotting. Data were measured as relative density (RD) of p-Akt/Akt, Cyclin D1/Actin, and PCNA/Actin. The first control lane was defined as 1 .

suppressed cell proliferation (from $30 \%$ to $19.6 \%$ EdUpositive cells, respectively, $p=0.0078$; Fig. 4B). The expression of the proliferation marker proliferating cell nuclear antigen (PCNA) was also decreased following Cx32 overexpression, and was induced in Cx32knockdown cells, as determined by western blot analysis (Fig. 4C). These results demonstrate the suppressing effect of Cx32 on HCC cell proliferation. Surprisingly, the expression of the cell cycle inhibitor $\mathrm{p} 21^{\text {Cip1/Wafl }}$ was also decreased in the Cx32-overexpressing SMMC-7721 cells. p21 is a p53 target gene, and $\mathrm{C} \times 32$ was shown to positively regulate the transcriptional activity of p53 (Fig. 3C); however, here it negatively regulated p21 expression. Therefore, we concluded that the effect of Cx32 on p21 expression was p53-independent and did not occur at the transcriptional level; thus, p21 might not be involved in the regulation of $\mathrm{HCC}$ proliferation by $\mathrm{Cx} 32$.

It is well known that Akt/PKB functions as a critical regulator of cell survival and proliferation, and that cyclin D1 is one of the most important regulatory proteins in cell cycle progression and can be modulated by the PI3K/Akt pathway [27]. Therefore, we examined the effects of Cx32 on the activation of Akt signaling and on cyclin D1 expression, by measuring the levels of phosphorylated
Akt and cyclin D1. Western blot analysis showed that the expression of cyclin D1 and phosphorylated Akt was significantly decreased when $\mathrm{Cx} 32$ was overexpressed in cells and was increased in Cx32-depleted cells (Fig. 4C).

These data indicate that $\mathrm{Cx} 32$ suppresses HCC proliferation through its ability to inhibit the phosphorylation and activity of Akt, and the expression of the cell cycle regulatory protein cyclin D1. This hypothesis was further supported by our results that showed that treatment with the PI3K/Akt inhibitor LY294002 drastically attenuated Cx32-mediated inhibition of cyclin D1 and PCNA expression (Fig. 4D). As shown in Figure 4D, transfection of Cx32 impaired Akt phosphorylation and the expression of cyclin D1 and PCNA, while in the LY294002 treatment group, Cx32 did not impair cyclin D1 and PCNA levels. Taken together, the results of the series of experiments described above demonstrated that $\mathrm{Cx} 32$ negatively regulated HCC cell proliferation via the Akt signaling pathway.

\section{Cx32 suppresses HCC progression in vivo}

To further investigate whether $\mathrm{C} \times 32$ suppresses $\mathrm{HCC}$ progression in vivo, $\mathrm{Cx} 32$ was stably knocked down 
in the highly metastatic HCC cell line MHCC97H. After subcutaneous transplantation of the $\mathrm{MHCC} 97 \mathrm{H}-\mathrm{shC}$ tlr and MHCC97H-shCx32 cell lines into nude mice, both groups successfully formed tumors 1 week later. The tumors of the MHCC97H-shCx32 model grew faster than those of the MHCC97H-shCtrl model (Fig. 5A, 5B). Significant differences were observed 19 days after transplantation $(p<0.01)$. Pulmonary metastasis was observed in MHCC97H-shCx32 mice, but not in the control group (Fig 5C). To correlate the biological response with the mechanisms identified in the cells, CD82 and PCNA protein levels were assessed by western blot analysis. As shown in Figure 5D, knockdown of Cx32 significantly suppressed the expression of CD82 and enhanced the expression of PCNA in transplanted tumor tissue. These data indicate that $\mathrm{Cx} 32$ was able to suppress $\mathrm{HCC}$ tumor growth and metastasis in nude mice.

\section{DISCUSSION}

It is known that $\mathrm{Cx}$ genes act as tumor suppressors by the maintenance of cellular homeostasis via gap junctional intercellular communication (GJIC). A growing amount of evidence has accumulated, suggesting that at least in some cases, Cxs exert their tumor suppressive effects through a gap junction channel-independent pathway [28]. In many cases, re-expression of Cxs in both non-metastatic and metastatic tumor cell lines results in decreased cell proliferation and tumorigenesis and promotes favorable mesenchymal to epithelial-like transitions [29, 30]. In this study, we showed that Cx32 suppressed HCC proliferation and invasion, based on observations from human specimens, as well as from in vitro assays. We presented evidence supporting the notion that the downregulation of Cx32 in human HCC tissues is associated with enhanced vascular invasion and larger tumor size. In vitro studies showed that depletion or overexpression of Cx32 in HCC exhibited a significant inhibitory effect of $\mathrm{Cx} 32$ on cell invasion, migration, and proliferation. Furthermore, we identified the p53 and Akt signaling pathways as two novel targets that are partly responsible for the anti-metastatic and anti-proliferative functions of $\mathrm{Cx} 32$. The findings of this study suggested a crucial inhibitory function of $\mathrm{Cx} 32$ in tumor migration, invasion, and proliferation (Fig. 6).

Our study further confirmed the role of $\mathrm{Cx} 32$ as an anti-invasive gene in HCC cells with a wild-type p53 background. These findings are consistent with those of numerous previous reports documenting the antiinvasive role of Cxs in glioma stem cells [31] and renal cell carcinoma [32]. However, Cxs are not consistently identified as tumor suppressors, and these proteins can facilitate tumor progression during late-stage disease.

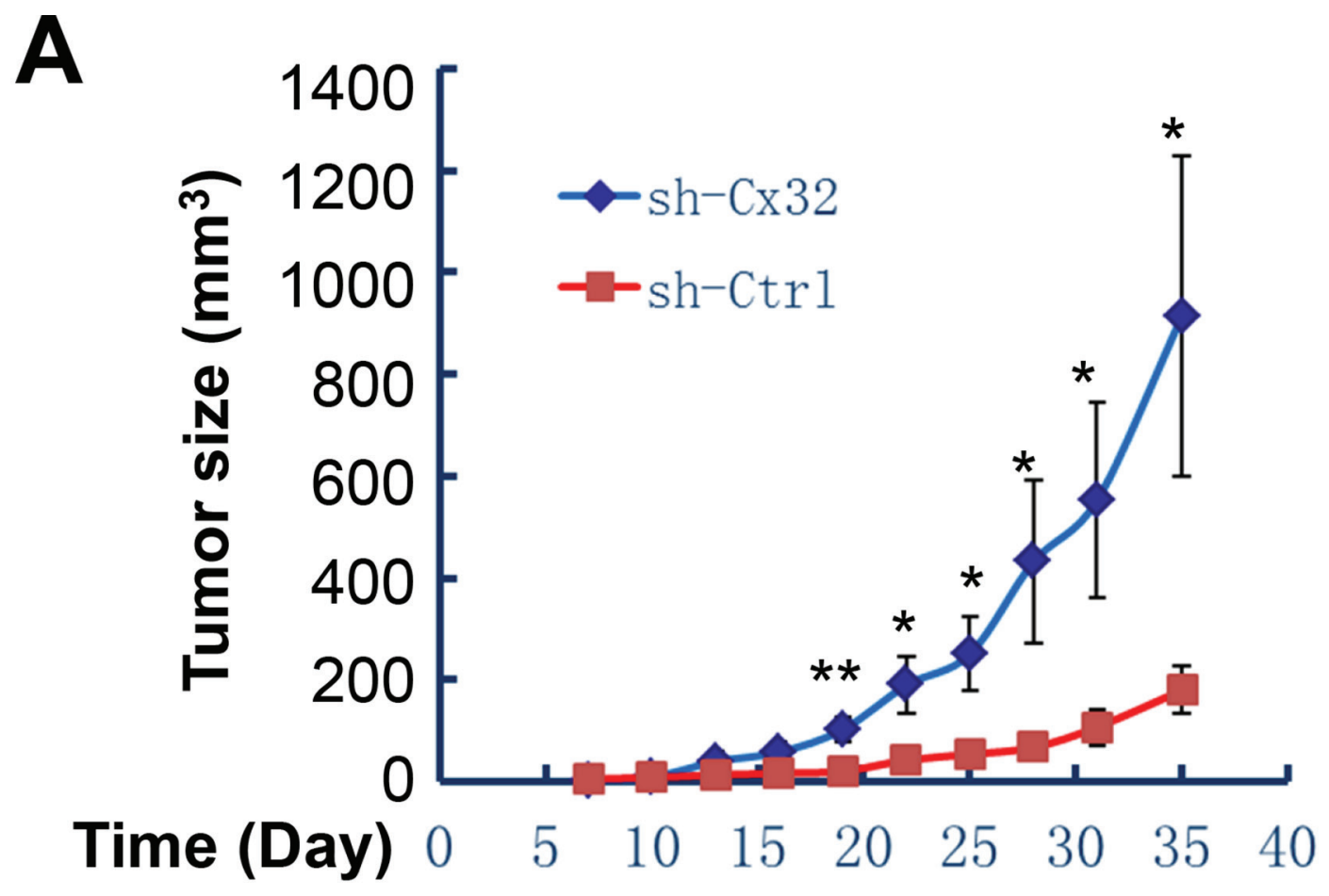

Figure 5: Cx32 suppresses HCC growth and pulmonary metastasis in mouse models. (A) Growth curves of the MHCC97HshCtrl and MHCC97H-shCx32 models.

(Continued) 
B
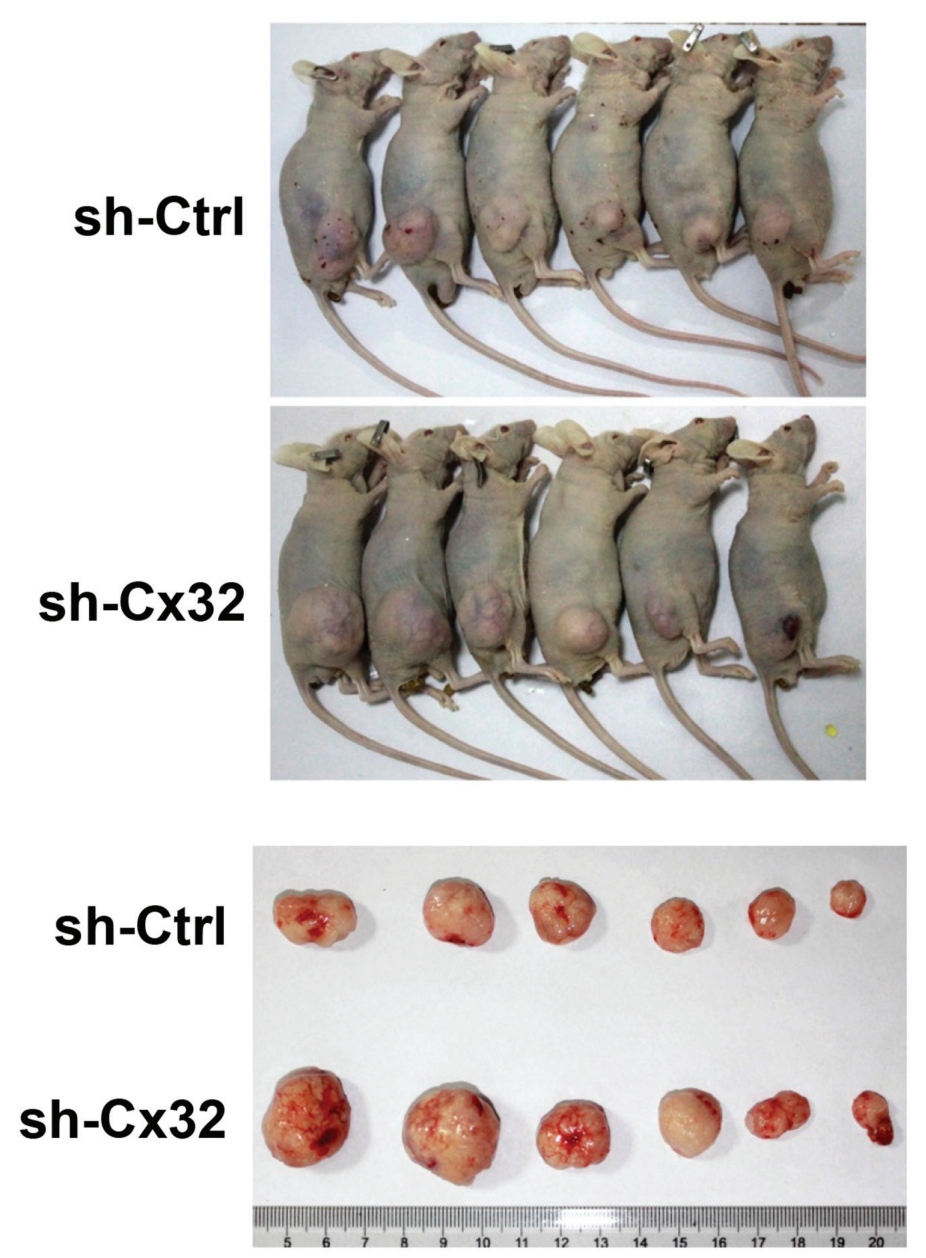

C

\section{MHCC97H-shCtrl MHCC97H-shCx32}

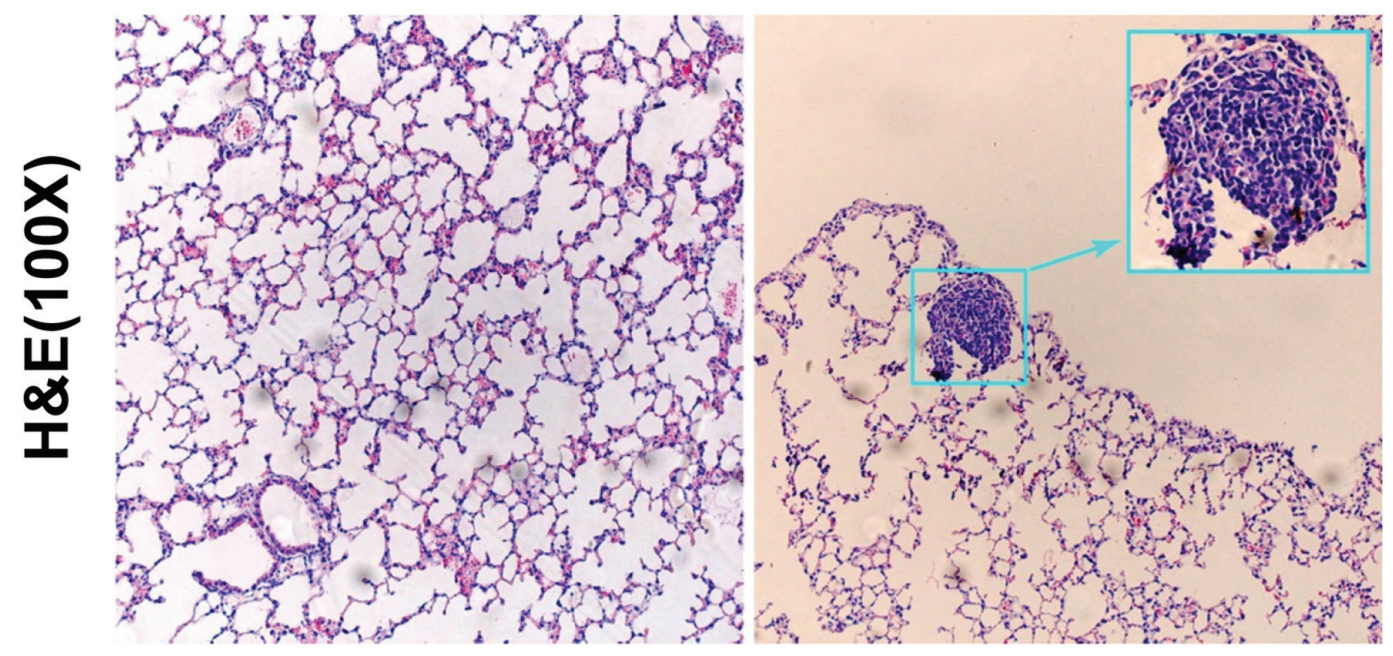

Figure 5 (Continued): (B) Macrograph of mice and tumors in both groups. (C) Hematoxylin and eosin (H\&E)-stained images of metastatic nodules in lungs. 
D

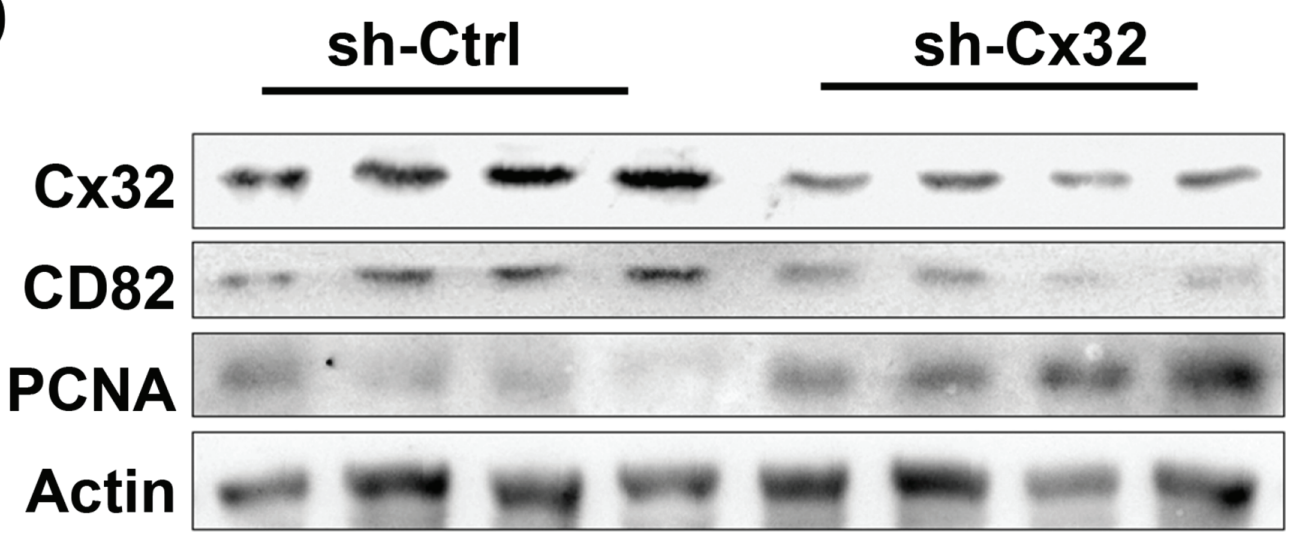

Figure 5 (Continued): (D) Western blot analysis of the expression of Cx32, CD82, and PCNA protein in MHCC97H-shCx32 tumors and control tumors; * $p<0.05$ and $* * p<0.01$.

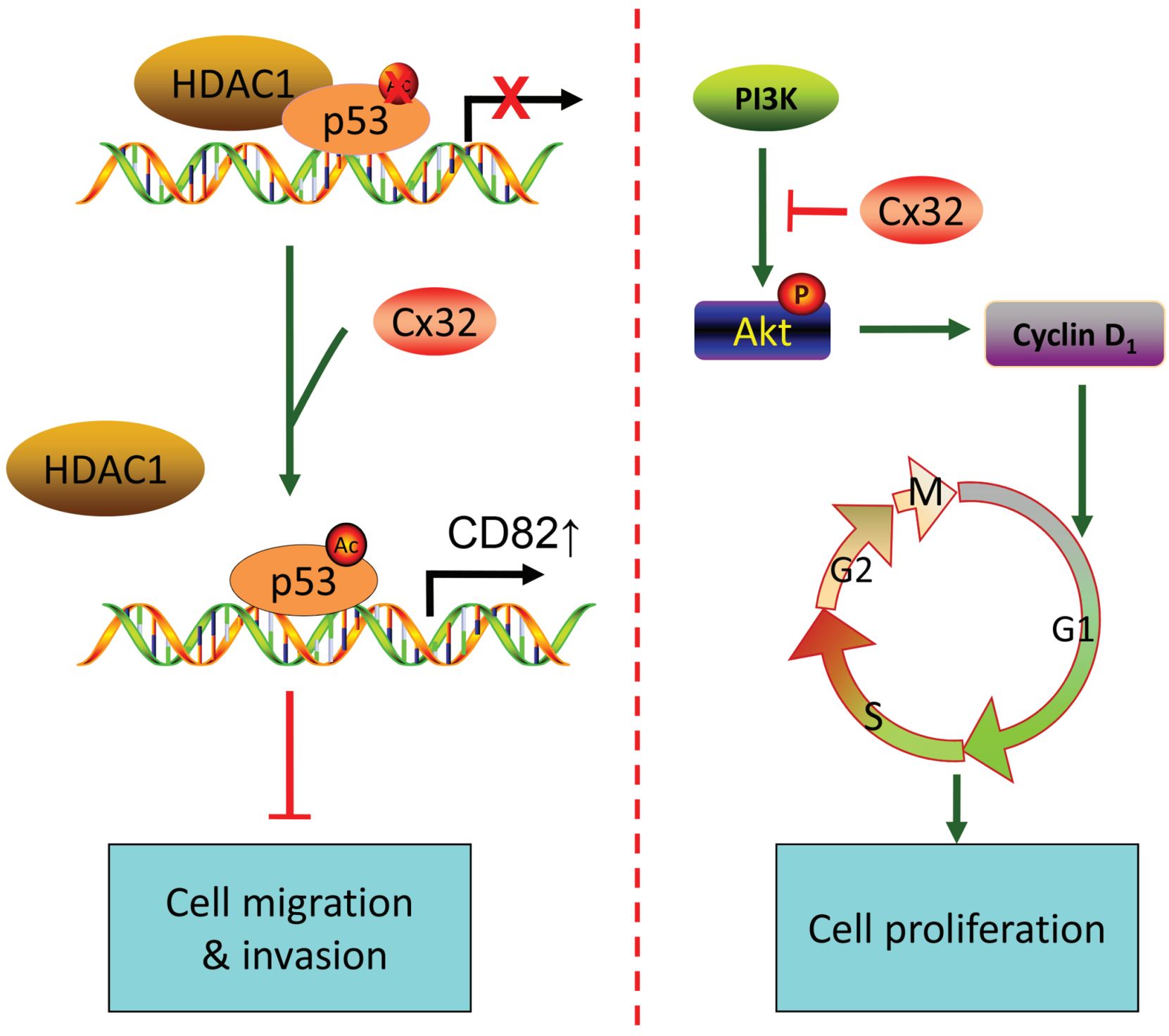

Figure 6: A proposed model for the mechanism by which $\mathrm{Cx32}$ suppresses metastasis and proliferation of $\mathrm{HCC}$ cells through the p53 and Akt pathways, respectively. 
Several reports suggest that Cxs might facilitate invasion and metastasis in human Huh7 HCC cells [11] and melanoma cells [33]. This leads one to consider the possibility that Cxs are differentially regulated during the development of specific tumor types. The role of Cxs in tumor cell invasion and metastasis seems to be complex and seems to depend on the different tumor types, $\mathrm{Cx}$ isoforms, and tumor progression stages. Even in the same type of cancer, Cx32 displays different functions in different cell lines. In a previous study of $\mathrm{Cx} 32$ in Huh7 cells, Cx32 facilitated invasion and metastasis [11], while in our study, an opposite effect of Cx32 on invasion and metastasis was demonstrated in HepG2 and SMMC-7721 cells.

In our study, p53 was a key regulatory protein involved in Cx32 function. In both the HepG2 and SMMC-7721 cell lines that harbor wild-type p53, Cx32 exerted an anti-invasive effect that was mediated by $\mathrm{p} 53$. However, Huh7 cells harbor a Y220C mutant p53 that is inactive, instead of a wild-type p53 [34]; thus, Cx32 may regulate cell invasion and metastasis through different mechanisms. Our study also indicated that in p53null Hep3B cells, Cx32 alone could weakly inhibit cell migration; these data demonstrated that the p53 pathway was partly responsible for the anti-metastatic function of Cx32. However, the detailed mechanism remains to be elucidated.

The involvement of Cxs in the regulation of tumor cell proliferation has been suggested by a number of recent studies. One study, in which Cx32 expression was depleted in rat hepatoma cells, showed that the magnitude of cell proliferation is inversely proportional to the level of Cx32 expression [15]. Another study on gastric cancer showed that $\mathrm{Cx} 32$ inhibits gastric cancer cell proliferation through cell cycle arrest and altered expression of p21 and p27 [16]. The results of our in vitro Cx32 overexpression and knockdown studies are in agreement with these results. The mechanisms by which Cxs regulate proliferation appear to be more complicated. $\mathrm{Cx} 43$ has been shown to modulate the expression of several genes involved in the cell cycle, including cyclin A, cyclin D1, and cyclin D2, the cyclin-dependent kinases [35], and p21 and p27 [36]. Cx32 may also regulate cell cycle progression via a different pathway.

Our study showed a positive effect of $\mathrm{Cx} 32$ on the p53 signaling pathway and a negative effect of $\mathrm{Cx} 32$ on the Akt signaling pathway. Whether cross-talk exists between these two signaling pathways in the regulation of Cx32 warrants further exploration. It has been shown that p53 inhibits the Akt/mTOR pathway [37, 38]; we hypothesize that, when activated by $\mathrm{Cx} 32$, p53 not only transcriptionally activates KAI1/CD82, but also inhibits the Akt/mTOR pathway, thereby suppressing HCC cell proliferation and metastasis. It has been shown that microRNA-137 suppresses tumor growth and metastasis in human hepatocellular carcinoma by targeting AKT2 [39]. On the other hand, the negative effect of Cx32 on the Akt signaling pathway may also affect metastasis of HCC more than proliferation.

In our study, Cx32 activated p53 and inhibited proliferation of HCC cells. It is surprising that the expression of p21, a p53 target gene and a potent cyclindependent kinase inhibitor, was also downregulated by Cx32. This phenomenon is in contrast to the findings reported in previous relevant studies $[16,36]$. We offer the following explanation for this discrepancy. First, p21 is not involved in the inhibitory function of $\mathrm{Cx} 32$ on HCC cell proliferation. Second, the inhibitory effect of $\mathrm{Cx} 32$ at the p21 protein level does not occur at the transcriptional level, but occurs instead at a post-transcriptional level. Cx32 inhibits the activity of Akt, and it has been reported that Akt phosphorylation of $\mathrm{p} 21^{\mathrm{Cip} / \mathrm{WAF} 1}$ enhances the stability of $\mathrm{p} 21^{\mathrm{Cip} / \mathrm{WAF} 1}$ and promotes cell survival [40]. Additionally, p21 exerts both positive and negative regulatory effects on cell cycle progression and is a regulator of cell survival. Finally, it is possible that Cx32 decreases p21 protein stability via Akt. Thus, the regulation of p21 expression by Cxs might vary according to the tumor type and $\mathrm{Cx}$ isoform. Additional studies are needed to elucidate Cx-mediated p21 expression mechanisms in HCC.

In conclusion, our study highlights the crucial role played by $\mathrm{Cx} 32$ in suppressing the progression of human $\mathrm{HCC}$ by inhibiting cell proliferation and invasiveness. Our data suggest that modulation of $\mathrm{Cx} 32$ could represent a future therapeutic strategy for the treatment of HCC.

\section{MATERIALS AND METHODS}

\section{Cell lines and animals}

The HCC cell lines HepG2, QGY-7701, SMMC7721, and Hep3B and the human embryonic kidney cell line HEK 293T were purchased from the cell bank of the Shanghai Institute of Cell Biology (Shanghai, China). The MHCC97-H cell line was obtained from the Shanghai Cancer Institute. Cells were cultured in Dulbecco's modified Eagle's medium (DMEM; Gibco, Invitrogen), supplemented with $10 \%$ fetal bovine serum (FBS; HyClone), $100 \mathrm{U} / \mathrm{ml}$ penicillin, and $100 \mathrm{U} / \mathrm{ml}$ streptomycin. BALB/c nu/nu mice were purchased from the National Rodent Laboratory Animal Resources, Shanghai branch. Mice were kept in pathogen-free conditions and cared for according to the Laboratory Animal Care guidelines. Adult male animals, aged 8 to 10 weeks, were used. All the experimental protocols were reviewed and approved by our institutional review board. All animal experimental protocols were approved by the Institutional Animal Care and Use Committee of Xiamen University. 


\section{Human tissue specimens}

Tumor samples were obtained with informed consent from HCC patients at Zhongshan Hospital Xiamen University, between 2007 and 2011. The study was approved by the Xiamen University Medical Ethics Committee. Overall survival was calculated from the date of surgery to the date of death or final follow-up.

\section{Vector construction}

The pcPUR+U6icassette plasmid, which contained an RNA interference sequence that targeted $\mathrm{Cx} 32$, was constructed as previously described [41]. Briefly, forward and reverse short-hairpin RNA (Table 2) that targeted $\mathrm{C} \times 32$ were annealed together and inserted into the $B s p \mathrm{MI}$ site of the pcPUR+U6icassette vector, thereby generating the pcPUR+U6-siCx32 plasmid.

\section{RNA interference and stable cell lines}

Small interfering RNA duplexes were purchased from RiboBio (Guangzhou, China). siRNAs were transfected using the HiPerFect siRNA transfection reagent (Qiagen), according to the manufacturer's instructions. To generate stably transfected cells, HepG2 or MHCC97H cells were transfected with pcPUR+U6-siCx32 or with control vectors by using the TurboFect transfection reagent (Fermentas) and stably transfected cells were established by treatment with $2 \mu \mathrm{g} / \mathrm{ml}$ puromycin for 3 weeks. The stable clones transfected with pcPUR+U6-siCx32 or pcPUR+U6 (control vector) are referred to as "shCx32" or "shCtrl," respectively.

\section{RNA extraction and real-time PCR}

Total RNA was extracted using the TRIzol reagent (Invitrogen, Carlsbad, CA), according to the manufacturer's instructions. Total RNA was reverse transcribed using the Prime Script TM RT reagent kit (Takara Biotechnology Dalian, China), according to the manufacturer's instructions. Quantitative real-time PCR was performed using the Maxima SYBR Green qPCR Master Mix (Fermentas). All values were normalized to the expression of the house-keeping gene glyceraldehyde3-phosphate dehydrogenase (GAPDH), and the relative expression was calculated according to the $2^{-\Delta C(t)}$ method: $\left[\Delta \mathrm{C}_{\mathrm{T}}=\mathrm{C}_{\mathrm{T}}(\mathrm{Cx} 32)-\mathrm{C}_{\mathrm{T}}(\mathrm{GAPDH})\right]$. The following primers were used: Cx32-F: TGTCATCAGCGTGGTGTTC, Cx32-R: TTGCGGGAAGGTGGATTG; GAPDH-F: TGGCAAAGTGGAGATTGTTGCC, GAPDH-R: AAGATGGTGATGGGCTTCCCG.

\section{Western blot analysis}

Equal amounts of protein lysates were separated by SDS-PAGE and were transferred onto PVDF membranes. The filters were probed with the following specific primary antibodies: Cx32 (Thermo), green fluorescent protein (GFP; Santa Cruz Biotechnology), histone deacetylase 1 (HDAC1; Proteintech), matrix metallopeptidase 2 (MMP2; Epitomics), vascular endothelial growth factor (VEGF; Thermo), proliferating cell nuclear antigen (PCNA; Abcam), betaactin (Sigma), acetylated-p53 (Upstate Biotechnology), p53, Akt, phosphorylated-Akt, cyclin D1, and p21 Cipl/Wafl (Cell Signaling Technology). The blots were then incubated with horseradish peroxidase-conjugated secondary antibodies (Pierce) and visualized by chemiluminescence.

\section{Immunohistochemistry}

Paraffin-embedded tissue samples were serially sectioned and immunohistochemically examined using an immunohistochemical staining kit (Maixin Bio, China), according to the manufacturer's instructions, with antibodies against $\mathrm{Cx} 32$ (Thermo).

Table 2: siRNAs targeting the $\mathrm{Cx32}$ gene

\begin{tabular}{|l|l|}
\hline Site 1 & $\begin{array}{l}\text { Sense-oligo: } \\
\text { 5'CACCCCGGCATTCTACTGCCATTACGTGTGCTGTCCGTAATGGCAGTAGAATGCCGG TTTTT 3' } \\
\text { Antisense-oligo: } \\
\text { 5'GCATAAAAACCGGCATTCTACTGCCATTACGGACAGCACACGTAATGGCAGTAGAATGCCGG 3' }\end{array}$ \\
\hline Site 2 & $\begin{array}{l}\text { Sense-oligo: } \\
\text { 5'CACCGCTGCAACAGCGTTTGCTAACGTGTGCTGTCCGTTAGCAAACGCTGTTGCAGCTTTTT 3' } \\
\text { Antisense-oligo: } \\
\text { 5'GCATAAAAAGCTGCAACAGCGTTTGCTAACGGACAGCACACGTTAGCAAACGCTGTTGCAGC 3' }\end{array}$ \\
\hline Site 3 & $\begin{array}{l}\text { Sense-oligo: } \\
\text { 5'CACCGGCTCACCAGCAACACATAACGTGTGCTGTCCGTTATGTGTTGCTGGTGAGCC TTTTT 3' } \\
\text { Antisense-oligo: } \\
\text { 5'GCATAAAAAGGCTCACCAGCAACACATAACGGACAGCACACGTTATGTGTTGCTGGTGAGCC 3' }\end{array}$ \\
\hline
\end{tabular}




\section{Luciferase reporter assay}

The cells were transfected with a p53-luciferase reporter plasmid, $\beta$-galactosidase ( $\beta$-gal), and additional expression vectors, as required. After transfection, cell lysates were prepared using the luciferase cell lysis buffer, and the luciferase and $\beta$-gal activities were measured. Luciferase activity was normalized to the transfection efficiency by using the corresponding $\beta$-gal activity. The ratios of the luciferase/ $\beta$-gal activity were used as indicators of the transcriptional activity of the p53 promoter. The bars represent the mean \pm SEM from three independent experiments.

\section{Tumor cell migration and invasion assays}

Cell migration was assayed using the transwell method, with $8-\mu \mathrm{m}$ pore filters (Corning, NY). The lower chamber was filled with Dulbecco's modified Eagle's medium (DMEM), supplemented with $10 \%$ fetal bovine serum (FBS), and $2 \times 10^{4}$ cells in $0.5 \mathrm{ml}$ of DMEM were loaded into the upper chamber. After a 22-hour incubation period, the cells that migrated to the bottom of the membrane were fixed with $4 \%$ formaldehyde. The cells on the top of the membrane were removed by wiping the surface with a cotton swab. The cells were stained with $0.5 \%$ crystal violet and observed under a microscope. The number of migrated cells was counted at a magnification of $200 \times$ from five adjacent microscope fields. For the Matrigel invasion assay, the procedures used were the same as those described above, except that the transwell membrane was coated with Matrigel (BD, CA, USA) to form a matrix barrier.

\section{EdU assay}

The EdU incorporation assay was performed using the EdU assay kit (RiboBio, Guangzhou, China), according to the manufacturer's instructions. Briefly, SMMC-7721 cells were cultured in triplicate in 24-well plates and transfected with the Cx32 vector for $36 \mathrm{~h}$. The cells were then incubated with $50 \mathrm{nM}$ EdU for an additional $2 \mathrm{~h}$ at $37^{\circ} \mathrm{C}$. The cells were fixed with $4 \%$ formaldehyde for $15 \mathrm{~min}$ at room temperature and treated with $0.5 \%$ Triton $\mathrm{X}-100$ for $20 \mathrm{~min}$ at room temperature to permeabilize them. After three washes with phosphate-buffered saline (PBS), the cells were incubated with the Apollo reaction cocktail $(100 \mu \mathrm{l} /$ well $)$ for $30 \mathrm{~min}$. The DNA was stained with $10 \mu \mathrm{g} / \mathrm{ml}$ of Hoechst 33342 dye $(100 \mu \mathrm{l} /$ well $)$ for $20 \mathrm{~min}$ and visualized with a fluorescence microscope.

\section{Wound healing assay}

The cells were transfected and grown in 6-well plates until they reached $100 \%$ confluence. Migration ability was assessed by measuring the movement of cells into a scraped, acellular area that was created by a sterile pipet tip. Wound closure was observed after $24 \mathrm{~h}$ and was photographed under a microscope. The fraction of cell coverage across the line represents the migration rate.

\section{In vivo assays for tumor growth and metastasis}

MHCC97H-shCtrl and MHCC97H-shCx32 cells $\left(5 \times 10^{6}\right)$ in $0.2 \mathrm{ml}$ of serum-free culture medium were inoculated subcutaneously into the right side of the backs of the nude mice. After a tumor formed, the tumor size was estimated according to the formula: volume $\left(\mathrm{mm}^{3}\right)$ $=\mathrm{a}^{2} \times \mathrm{b} / 2$, where "a" is the major diameter of the tumor and " $\mathrm{b}$ " is the minor diameter perpendicular to the major one [42]. Eight weeks later, the animals were sacrificed. The tumors were removed and cryopreserved at $-70^{\circ} \mathrm{C}$ for western blot analysis. Lungs were removed and embedded in paraffin for hematoxylin and eosin (H\&E) staining.

\section{Co-IP assay}

Cells were lysed in lysis buffer supplemented with protease inhibitors. Immunoprecipitation and western blot analyses were performed as previously described [43]. Briefly, the cell lysate was incubated with the appropriate antibody and protein A-agarose beads for $3 \mathrm{~h}$. The immunoprecipitate was collected, washed three times with lysis buffer, and examined using western blot analysis with different antibodies, as required, after separation by SDSPAGE. The immunoreactive products were visualized via enhanced chemiluminescence.

\section{Statistical analyses}

The data were analyzed using GraphPad Prism, version 5 (GraphPad Software, Inc., San Diego, CA). The results are expressed as the mean \pm SEM. Statistical analyses of normally distributed variables were performed using the Student's $t$-test, and analyses of data with skewed distributions were performed using the MannWhitney $U$-test. The relationship between the overall survival time and the Cx32 level was analyzed with Kaplan-Meier survival curves and the log-rank test. $p<0.05$ was considered statistically significant.

\section{ACKNOWLEDGEMENTS}

We would like to sincerely thank Prof. Wei-Guo Zhu (Peking University Health Science Center, China) for providing the p53 mutant (K373R/K382R) expression plasmids, Bayasi Guleng (Zhongshan Hospital Xiamen University) for providing the pcPUR+U6icassette vector, and Jennifer Orthmann-Murphy (University of Pennsylvania Medical Center, Philadelphia, PA) for providing the pIRES2-EGFP-Cx32 expression plasmid. 


\section{Grant support}

This work was supported by grants from the National Natural Science Foundation of China (No. 81302069 and No. 81171976), the National Key Sci-Tech Special Project of China (2012ZX10002-011-005), the National Key Basic Research Program of China (2013CB933904), the China Postdoctoral Science Foundation (2013M531550), the Natural Science Foundation of Fujian Province, China (2012D055), and the Projects of Xiamen Science and Technology Program (No. 3502Z20130030).

\section{Conflicts of interest}

The authors disclose no potential conflicts of interest.

\section{REFERENCES}

1. Farazi PA, DePinho RA. Hepatocellular carcinoma pathogenesis: from genes to environment. Nat Rev Cancer. 2006; 6:674-687.

2. Moeini A, Cornella H, Villanueva A. Emerging signaling pathways in hepatocellular carcinoma. Liver Cancer. 2012; 1:83-93.

3. Xie Q, Su Y, Dykema K, Johnson J, Koeman J, De Giorgi V, Huang A, Schlegel R, Essenburg C, Kang L, Iwaya K, Seki S, Khoo SK, Zhang B, Buonaguro F, Marincola FM, et al. Overexpression of HGF Promotes HBV-Induced Hepatocellular Carcinoma Progression and Is an Effective Indicator for Met-Targeting Therapy. Genes Cancer. 2013; 4:247-260.

4. Bjornsti MA, Houghton PJ. The TOR pathway: a target for cancer therapy. Nat Rev Cancer. 2004; 4:335-348.

5. Tai WT, Cheng AL, Shiau CW, Huang HP, Huang JW, Chen PJ, Chen KF. Signal transducer and activator of transcription 3 is a major kinase-independent target of sorafenib in hepatocellular carcinoma. J Hepatol. 2011; 55:1041-1048.

6. Vinken M, Henkens T, De Rop E, Fraczek J, Vanhaecke T, Rogiers V. Biology and pathobiology of gap junctional channels in hepatocytes. Hepatology. 2008; 47:1077-1088.

7. Mroue RM, El-Sabban ME, Talhouk RS. Connexins and the gap in context. Integr Biol (Camb). 2011; 3:255-266.

8. Laird DW. Life cycle of connexins in health and disease. Biochem J. 2006; 394:527-543.

9. Willecke K, Eiberger J, Degen J, Eckardt D, Romualdi A, Guldenagel M, Deutsch U, Sohl G. Structural and functional diversity of connexin genes in the mouse and human genome. Biol Chem. 2002; 383:725-737.
10. Fitzgerald DJ, Yamasaki H. Tumor promotion: models and assay systems. Teratog Carcinog Mutagen. 1990; 10:89-102.

11. Li Q, Omori Y, Nishikawa Y, Yoshioka T, Yamamoto Y, Enomoto K. Cytoplasmic accumulation of connexin32 protein enhances motility and metastatic ability of human hepatoma cells in vitro and in vivo. Int $\mathrm{J}$ Cancer. 2007; 121:536-546.

12. Ezumi K, Yamamoto H, Murata K, Higashiyama M, Damdinsuren B, Nakamura Y, Kyo N, Okami J, Ngan CY, Takemasa I, Ikeda M, Sekimoto M, Matsuura N, Nojima H, Monden M. Aberrant expression of connexin 26 is associated with lung metastasis of colorectal cancer. Clin Cancer Res. 2008; 14:677-684.

13. Elzarrad MK, Haroon A, Willecke K, Dobrowolski R, Gillespie MN, Al-Mehdi AB. Connexin-43 upregulation in micrometastases and tumor vasculature and its role in tumor cell attachment to pulmonary endothelium. BMC Med. 2008; 6:20.

14. Cronier L, Crespin S, Strale PO, Defamie N, Mesnil M. Gap junctions and cancer: new functions for an old story. Antioxid Redox Signal. 2009; 11:323-338.

15. Edwards GO, Jondhale S, Chen T, Chipman JK. A quantitative inverse relationship between connexin32 expression and cell proliferation in a rat hepatoma cell line. Toxicology. 2008; 253:46-52.

16. Jee H, Lee SH, Park JW, Lee BR, Nam KT, Kim DY. Connexin32 inhibits gastric carcinogenesis through cell cycle arrest and altered expression of p21Cip1 and p27Kip1. BMB Rep. 2013; 46:25-30.

17. Burt JM, Nelson TK, Simon AM, Fang JS. Connexin 37 profoundly slows cell cycle progression in rat insulinoma cells. Am J Physiol Cell Physiol. 2008; 295: C1103-1112.

18. Sanches DS, Pires CG, Fukumasu H, Cogliati B, Matsuzaki P, Chaible LM, Torres LN, Ferrigno CR, Dagli ML. Expression of connexins in normal and neoplastic canine bone tissue. Vet Pathol. 2009; 46:846-859.

19. Xu HT, Li QC, Zhang YX, Zhao Y, Liu Y, Yang ZQ, Wang EH. Connexin 43 recruits E-cadherin expression and inhibits the malignant behaviour of lung cancer cells. Folia Histochem Cytobiol. 2008; 46:315-321.

20. Wang R, Zhao N, Li S, Fang JH, Chen MX, Yang J, Jia WH, Yuan Y, Zhuang SM. MicroRNA-195 suppresses angiogenesis and metastasis of hepatocellular carcinoma by inhibiting the expression of VEGF, VAV2, and CDC42. Hepatology. 2013; 58:642-653.

21. Mashimo T, Watabe M, Hirota S, Hosobe S, Miura K, Tegtmeyer PJ, Rinker-Shaeffer CW, Watabe K. The expression of the KAI1 gene, a tumor metastasis suppressor, is directly activated by p53. Proc Natl Acad Sci U S A. 1998; 95:11307-11311. 
22. Gu W, Shi XL, Roeder RG. Synergistic activation of transcription by CBP and p53. Nature. 1997; 387:819-823.

23. Ito A, Kawaguchi Y, Lai CH, Kovacs JJ, Higashimoto Y, Appella E, Yao TP. MDM2-HDAC1-mediated deacetylation of p53 is required for its degradation. Embo $\mathrm{J}$. 2002; 21:6236-6245.

24. Murata M, Kojima T, Yamamoto T, Go M, Takano K, Chiba H, Tokino T, Sawada N. Tight junction protein MAGI-1 is up-regulated by transfection with connexin 32 in an immortalized mouse hepatic cell line: cDNA microarray analysis. Cell Tissue Res. 2005; 319:341-347.

25. Juan LJ, Shia WJ, Chen MH, Yang WM, Seto E, Lin YS, Wu CW. Histone deacetylases specifically down-regulate p53-dependent gene activation. J Biol Chem. 2000; 275:20436-20443.

26. Wei S, Xiong M, Zhan DQ, Liang BY, Wang YY, Gutmann DH, Huang ZY, Chen XP. Ku80 functions as a tumor suppressor in hepatocellular carcinoma by inducing S-phase arrest through a p53-dependent pathway. Carcinog enesis. 2012; 33:538-547.

27. Chang F, Lee JT, Navolanic PM, Steelman LS, Shelton JG, Blalock WL, Franklin RA, McCubrey JA. Involvement of PI3K/Akt pathway in cell cycle progression, apoptosis, and neoplastic transformation: a target for cancer chemotherapy. Leukemia. 2003; 17:590-603.

28. Naus CC, Laird DW. Implications and challenges of connexin connections to cancer. Nat Rev Cancer. 2010; 10:435-441.

29. McLachlan E, Shao Q, Wang HL, Langlois S, Laird DW. Connexins act as tumor suppressors in three-dimensional mammary cell organoids by regulating differentiation and angiogenesis. Cancer Res. 2006; 66:9886-9894.

30. Kalluri R, Weinberg RA. The basics of epithelialmesenchymal transition. J Clin Invest. 2009; 119:1420-1428.

31. Yu SC, Xiao HL, Jiang XF, Wang QL, Li Y, Yang XJ, Ping YF, Duan JJ, Jiang JY, Ye XZ, Xu SL, Xin YH, Yao XH, Chen JH, Chu WH, Sun W, et al. Connexin 43 reverses malignant phenotypes of glioma stem cells by modulating E-cadherin. Stem Cells. 2012; 30:108-120.

32. Yano T, Fujimoto E, Hagiwara H, Sato H, Yamasaki H, Negishi E, Ueno K. Connexin 32 as an anti-invasive and anti-metastatic gene in renal cell carcinoma. Biol Pharm Bull. 2006; 29:1991-1994.

33. Saito-Katsuragi $M$, Asada $H$, Niizeki $H$, Katoh $F$, Masuzawa M, Tsutsumi M, Kuniyasu H, Ito A, Nojima H, Miyagawa S. Role for connexin 26 in metastasis of human malignant melanoma: communication between melanoma and endothelial cells via connexin 26. Cancer. 2007; 110:1162-1172.
34. Hsu IC, Tokiwa T, Bennett W, Metcalf RA, Welsh JA, Sun T, Harris CC. p53 gene mutation and integrated hepatitis B viral DNA sequences in human liver cancer cell lines. Carcinogenesis. 1993; 14:987-992.

35. Chen SC, Pelletier DB, Ao P, Boynton AL. Connexin43 reverses the phenotype of transformed cells and alters their expression of cyclin/cyclin-dependent kinases. Cell Growth Differ. 1995; 6:681-690.

36. Sanchez-Alvarez R, Paino T, Herrero-Gonzalez S, Medina JM, Tabernero A. Tolbutamide reduces glioma cell proliferation by increasing connexin43, which promotes the up-regulation of p21 and p27 and subsequent changes in retinoblastoma phosphorylation. Glia. 2006; 54 : 125-134.

37. Korotchkina LG, Leontieva OV, Bukreeva EI, Demidenko ZN, Gudkov AV, Blagosklonny MV. The choice between $\mathrm{p} 53$-induced senescence and quiescence is determined in part by the mTOR pathway. Aging (Albany NY). 2010; 2:344-352.

38. Demidenko ZN, Korotchkina LG, Gudkov AV, Blagosklonny MV. Paradoxical suppression of cellular senescence by p53. Proc Natl Acad Sci U S A. 2010; 107:9660-9664.

39. Liu LL, Lu SX, Li M, Li LZ, Fu J, Hu W, Yang YZ, Luo RZ, Zhang CZ, Yun JP. FoxD3-regulated microRNA-137 suppresses tumour growth and metastasis in human hepatocellular carcinoma by targeting AKT2. Oncotarget. 2014; 5:5113-5124.

40. Li Y, Dowbenko D, Lasky LA. AKT/PKB phosphorylation of $\mathrm{p} 21 \mathrm{Cip} / \mathrm{WAF} 1$ enhances protein stability of p21Cip/WAF1 and promotes cell survival. J Biol Chem. 2002; 277:11352-11361.

41. Jazag A, Ijichi $H$, Kanai $F$, Imamura $T$, Guleng $B$, Ohta M, Imamura J, Tanaka Y, Tateishi K, Ikenoue T, Kawakami T, Arakawa Y, Miyagishi M, Taira K, Kawabe T, Omata M. Smad4 silencing in pancreatic cancer cell lines using stable RNA interference and gene expression profiles induced by transforming growth factorbeta. Oncogene. 2005; 24:662-671.

42. Wang L, Tang ZY, Qin LX, Wu XF, Sun HC, Xue Q, Ye SL. High-dose and long-term therapy with interferonalfa inhibits tumor growth and recurrence in nude mice bearing human hepatocellular carcinoma xenografts with high metastatic potential. Hepatology. 2000; 32:43-48.

43. Zhao BX, Chen HZ, Lei NZ, Li GD, Zhao WX, Zhan YY, Liu B, Lin SC, Wu Q. p53 mediates the negative regulation of MDM2 by orphan receptor TR3. Embo J. 2006; 25:5703-5715. 